\title{
\#DigPed Narratives in Education: Critical Perspectives on Power and Pedagogy
}

\author{
Suzan Koseoglu \\ Goldsmith, University of London, London, United Kingdom
}

Aras Bozkurt

Anadolu University, Eskişehir, Turkey, and University of South Africa, Pretoria, South Africa

\begin{abstract}
This mixed methods study addresses a knowledge gap in the nature and effects of networked scholarship. We analyze \#DigPed, a Twitter hashtag on critical pedagogy, through the lens of Tufekci's capacities and signals framework in order to understand how educational narratives develop and spread on \#DigPed. Using social network analysis and thematic analysis of content, we identify three prominent narratives in the network and discuss the network structures from a critical perspective. Based on the findings, we propose pedagogic capacity the power to initiate a productive and potentially transformative educational discourse, within oneself and within communities - as an additional lens to explore the spread and impact of critical narratives in education. Findings confirm the view that networked spaces are organized by hidden hierarchies marked by influence.
\end{abstract}

Keywords: \#DigPed, critical online pedagogy, gatekeeping, hashtag community, networked participatory scholarship, pedagogic capacity, Twitter

Koseoglu, S., \& Bozkurt, A. (2018). \#DigPed narratives in education: critical perspectives on power and pedagogy. Online Learning, 22(3), 157-174. doi:10.24059/olj.v22i3.1370

\section{\#DigPed Narratives in Education: Critical Perspectives on Power and Pedagogy}

When boyd (2010) coined the term networked publics, which she defined as "publics that have been transformed by networked media, its properties, and its potential" (p. 42), the idea of collective digital spaces was relatively new among scholars. For many, participation in networked spaces was not part of everyday academic practice or even vocabulary. Yet, these spaces have increasingly become places for public scholarship. Twitter in particular, with its ease of use and capacity to build personal learning networks, has quickly become a place for networked participatory scholarship (Veletsianos \& Kimmons, 2012), or simply put, academic participation. Stewart (2016) commented that "scholars who are isolated, disillusioned, marginalized, or junior in their institutional scholarship" could have a voice on Twitter, building identity and meaningful connections. However, as Stewart (2016) also noted, the form and "effects of networked scholarship" are understudied in education (p. 62). In this study, we address this ignored yet significant area of research by exploring a Twitter hashtag with a focus on digital pedagogy: \#DigPed. 


\section{Background}

Hashtags can be defined as "the practice of adding a keyword, or set of keywords, to a Twitter post" (Koutropoulos et al., 2014, p. 12). These keywords allow users to categorize messages, and as such they are "ad-hoc solutions" (p. 12) to organize and make sense of incoming and outgoing messages. The creation of hashtags is not just a technical solution to make sense of abundant information in an open platform; they are also communicative acts. Yang (2016) argues that hashtags are narrative forms because they tell stories (for example, the hashtag \#BlackLivesMatter and the associated movement began after the tragic death of African-American teenager Trayvon Martin). By posting a tweet with a hashtag, we invite people to participate in the "co-production of stories" (Yang, 2016, p. 14); however, there are no temporal or communal boundaries to these stories. As long as the platform exists, any post can be quoted, retweeted, liked and commented on anytime, by anyone.

Recent studies suggest that educators increasingly use Twitter for building personal learning networks and for professional development opportunities that do not necessarily fit into traditional practices (Carpenter \& Krutka, 2014; Veletsianos, 2012). In a mixed methods study, Forte, Humphreys, and Park (2012) observed that Twitter was a powerful tool to bridge new ideas circulating on networks with local communities. The authors noted the following:

We argue that this "bridging" activity not only helps teachers generate social capital that can help them succeed in their careers, but that it is the kind of social substrate that is necessary for education reform efforts to take root as like-minded individuals strengthen one another's ability to effect change. (p. 106)

Hence, the authors posited that teachers' activities on Twitter could be considered "grassroots professional development efforts" with transformative power (p. 106). Similarly, Fang (2016) asserted, "[e]veryone's journey towards self-transformation is unique. For many, it is likely to begin with a hashtag" (p. 141).

Yet, access to digital networks does not necessarily prompt meaningful participation, as many scholars have noted before us. Resistance to open structures might occur, especially if they seem unfamiliar or if they are not part of everyday practices (Iiyoshi \& Vijay Kumar, 2008). Active participation on a platform like Twitter also requires users to have certain digital literacy skills, such as finding the right balance between private and personal, being able to weed out fake or irrelevant information, and having an awareness of their imagined and real audience. This digital literacy skillset is particularly important for users to develop in hashtag communities because "network platforms are increasingly recognized as sites of rampant misogyny, racism, and harassment" (Stewart, 2016, p. 62). In addition, the stories told via hashtags, may not be very linear, or clear-cut, as in traditional narrative forms. Users can create secondary hashtags by creating, using, and disseminating additional keywords, thus creating and promoting the growth of subcommunities. However, the flow of information (the number of stories told) and participation patterns can be chaotic, as the perception of time is vague in these spaces, and hashtags have the potential to link past, present, and future communities.

Another important issue to bear in mind is the values inherent in technology. As Veletsianos and Kimmons (2012) noted, "practices developing in conjunction with emergent technologies (e.g., Facebook, Twitter, Google) will be influenced by the embedded values of those technologies and that not all of these influences may be positive" (p. 179). For example, Twitter algorithms may gently force or unconsciously lead us to swim in our own bubbles. Indeed, citing Gillespie (2014), Bruns and Burgess (2015) argue that we need to consider the shift from networked public and ad hoc publics "to personalised, calculated publics" because of the algorithms that are imposed on us (p. 25). 
Considering the unique affordances of the Twitter platform-both negative and positive-we seek to understand the kinds of narratives that spread in the \#DigPed network and their nature, as further explained in detail below.

\section{Research Context}

Digital Pedagogy Lab (DPL; http://www.digitalpedagogylab.com/) is a project that is committed to the "ongoing investigation and creative implementation of critical and digital pedagogies" (DPL, n.d.). As such, the project is "not ideologically neutral" and is influenced by the work of seminal critical pedagogues like Paulo Freire and bell hooks. Through face-toface and online professional development opportunities and educational outreach, contributors to DPL aim to deepen the conversation around critical approaches to education and empower both learners and teachers.

DPL is present on Twitter (@DigPedLab) and uses the hashtag \#DigPed to reach a broader audience and engage people with critical pedagogy. This research focuses on the \#DigPed activities during three DPL events: Digital Pedagogy Lab Cairo (March 20-22, 2016), Digital Pedagogy Lab PEI (July 13-15, 2016), and Digital Pedagogy Lab 2017 Summer Institute (August 7-11, 2017). These were face-to-face professional development events with online components, such as virtual meetings, Twitter chats, and blogging.

\section{Conceptual Framework}

In this study, we explored \#DigPed posts during three DPL events held between 2015 and 2017. The initial goal was to understand how educational narratives developed and spread on \#DigPed and the nature of their capacities using Tufekci's (2017) capacities and signals framework as an orienting lens. Here, by educational narrative, we refer to educational stories - in other words, a series of connected events, created via the use of hashtags.

Tufekci argues that the strength of social movements does not lie in their size or scale; rather, "strength of social movements lie in their capacities," and these capacities are signaled through collective action and impact. Here capacity means the power to successfully spread a vision ("setting the narrative") and change policy and practice ("effect electoral or institutional changes, and to disrupt the status quo") (2017, p. 191). Tufekci describes three arenas of capacity in her analysis:

1. Narrative capacity: "The ability of the movement to frame its story on its own terms, to spread its worldview" (p. 192).

2. Disruptive capacity: The ability of the movement to "interrupt the regular operations of a system of authority" (p. 192).

3. Electoral or institutional capacity: The ability to force political and institutional changes through both "insider and outsider strategies" (p. 192-193). (In this research, we do not focus on electoral capacity due to the research scope.)

We used the capacities and signals framework because it allows us to ask intriguing questions about the power and impact of hashtag communities on educational practice. Using the capacities and signals framework, we conceptualize Twitter as a politically charged public space, where educators occasionally act against mainstream models and common practices in education through a complex interplay of individual performance, spontaneous interactions with others, and organized structured and semistructured events. We acknowledge the fact that \#DigPed chats are not intended as protests in a traditional sense, and using a sociopolitical framework to analyze its activities as political movements may seem unfitting. However, as we noted above, DPL is a project which is not ideologically neutral: It is inspired by postcolonial movements in education. Perhaps because of this ideological positioning, 
discursive protests against mainstream models and practices in education are often present on \#DigPed, whether intentional or through spontaneous interactions.

Second, our goal was not to adopt the conceptual framework blindly. Rather, we used it as a starting point to ask such questions and embraced a critical perspective to be able to discuss to what extent the framework may apply to the unique context of \#DigPed. We also intended to explore whether the framework was sufficient to explain educational narratives or whether we needed any other capacity type for such instances.

\section{Research Question}

The purpose of this research was to examine \#DigPed conversations through the lens of the capacities and signals framework. The overarching research question that guided this research was this: How do educational narratives develop and spread on \#DigPed?

\section{Methods}

\section{Research Design}

In this study, a transformative mixed methods design is used. Different from basic mixed methods designs, transformative mixed methods design encases the design within a conceptual framework (i.e., in the context of this study, the capacities and signals framework) and benefits from it as an overall orienting lens (Creswell \& Plano Clark, 2011). This type of mixed design is value based and ideological (Greene, 2007), and the adopted framework shapes many aspects of the research, such as data collection, analysis, and interpretation (Creswell, 2012).

\section{Data Sources}

The main data corpus included both quantitative (numeric) and qualitative (textual and visual) data. The primary data source was all the Twitter posts tagged with \#DigPed during the three DPL events. Secondary data sources were information on DPL event websites, keynotes, and blog posts linked to Twitter posts.

\section{Sampling}

By adopting a convenience sampling strategy, all Twitter posts tagged with \#DigPed during three DPL events were sampled. These events were held between 2015 and 2017. We analyzed 385 interactions among 175 participants in \#DigPed Cairo, 115 interactions among 75 participants in \#DigPed PEI, and 530 interactions among 229 participants in the \#DigPed 2017 Summer Institute.

\section{Data Collection \& Analysis}

Social network analysis (SNA; Hansen, Shneiderman, \& Smith, 2010) was used as a starting point in this research. To do this, all network activities in three DPL events were collected with an SNA software called NodeXL. Following that, local and global network metrics were calculated for each event, and sociograms were created based on these metrics to examine the network patterns. To visualize sociograms, grid layout (Hansen et al., 2010) was selected, and nodes were grouped into clusters using the Clauset-Newman-Moore cluster algorithm (Clauset, Newman, \& Moore, 2004). In addition, we examined other metrics provided by the software, such as top URLs, top domains, top hashtags, and top words used for each event.

We then employed thematic analysis using the constant comparative method (Charmaz, 2006; Tracy, 2013) to (a) contextualize findings obtained from the SNA and (b) identify 
prominent narratives that had spread on the network. This part of the study was approached through an interpretive paradigm; that is, we acknowledged the fact that knowledge is "socially constructed through language and interaction" and is always partial (Tracy, 2013, p. 41). Thus, we sought understanding through self-reflexivity and iterative cycles of data analysis. We kept a collaborative researcher journal to increase our self-reflexivity and as a space to document our thoughts.

Thematic analysis began with the data provided by NodeXL. The program provides useful information, such as all tweets posted and their weight in the network (the posts that gained the most attention in the network) and the most commonly used hashtags and words. We first made a note of data that piqued our interest. For example, in \#DigPed Cairo, love was one of the most common words used in few clusters of activity. However, what did that mean in context? In order to better understand the context of quantified information and to identify other possible prominent themes in the network, we then examined the \#DigPed posts for each DPL event using thematic analysis.

First, both researchers read all the event tweets and noted initial impressions. They then had a meeting to discuss these initial thoughts and ideas. After this initial exploratory stage, Researcher A began coding all tweets in a more systematic manner. Tweets were open coded using a codebook, and codes within and across events were refined in an iterative manner (for an example of open codes, see Appendix A). The next step was to identify common codes within and across each event through axial coding. At this stage, Researcher B was invited to review the emerging codes and note areas of concern. Finally, after the researchers reached consensus, the codes that were most relevant to the goals of the research study were chosen through selective coding. While doing that, additional data sources linked to the posts - such as event websites, streamed keynote sessions, and blog posts - were also examined to further contextualize the data. For example, after analyzing all the tweets for \#DigPed 2017 Summer Institute, we understood why www.theedadvocate.org appeared as one of the most visited domains in the SNA (further discussed in the Findings section). Multiple readings of both SNA and event tweets were required to make such connections. Researchers regularly held online meetings and had chats to discuss such emergent findings.

During the research process, reflections and questions arising from the analysis were noted in the coding documents where appropriate and in the researchers' shared reflective journal (for an example, see Appendix B).

\section{Results}

\section{Social Network Analysis}

Network patterns. We first created a visual representation of the social relationships within the network using a sociogram (Figures 1, 2, and 3). In sociograms, each node represents an individual in the network and each tie represents an interaction/conversation among them. Local and global network metrics were calculated, and sociograms for each event were created based on these metrics. To visualize sociograms, grid layout was selected, and nodes were grouped by cluster using the Clauset-Newman-Moore cluster algorithm (Clauset, Newman, \& Moore, 2004). The tie colors, widths, and opacities are based on edge weight values. The edge widths are based on edge weight values. The nodes' sizes and opacities are based on betweenness centrality values. The colors of the nodes were randomly assigned according to the clusters they belong to. 


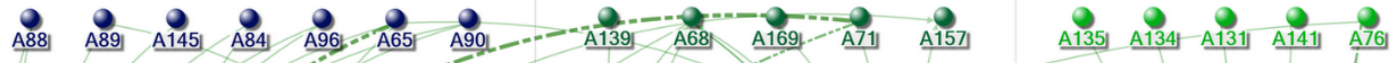

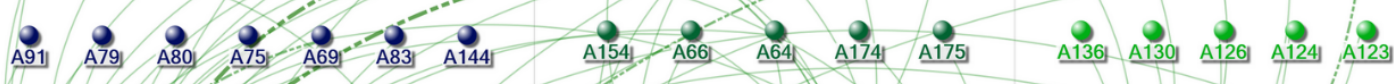

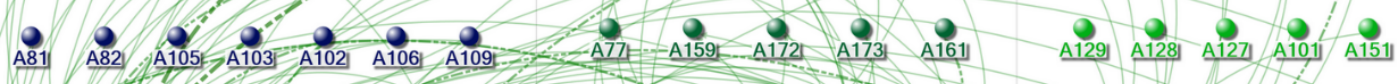

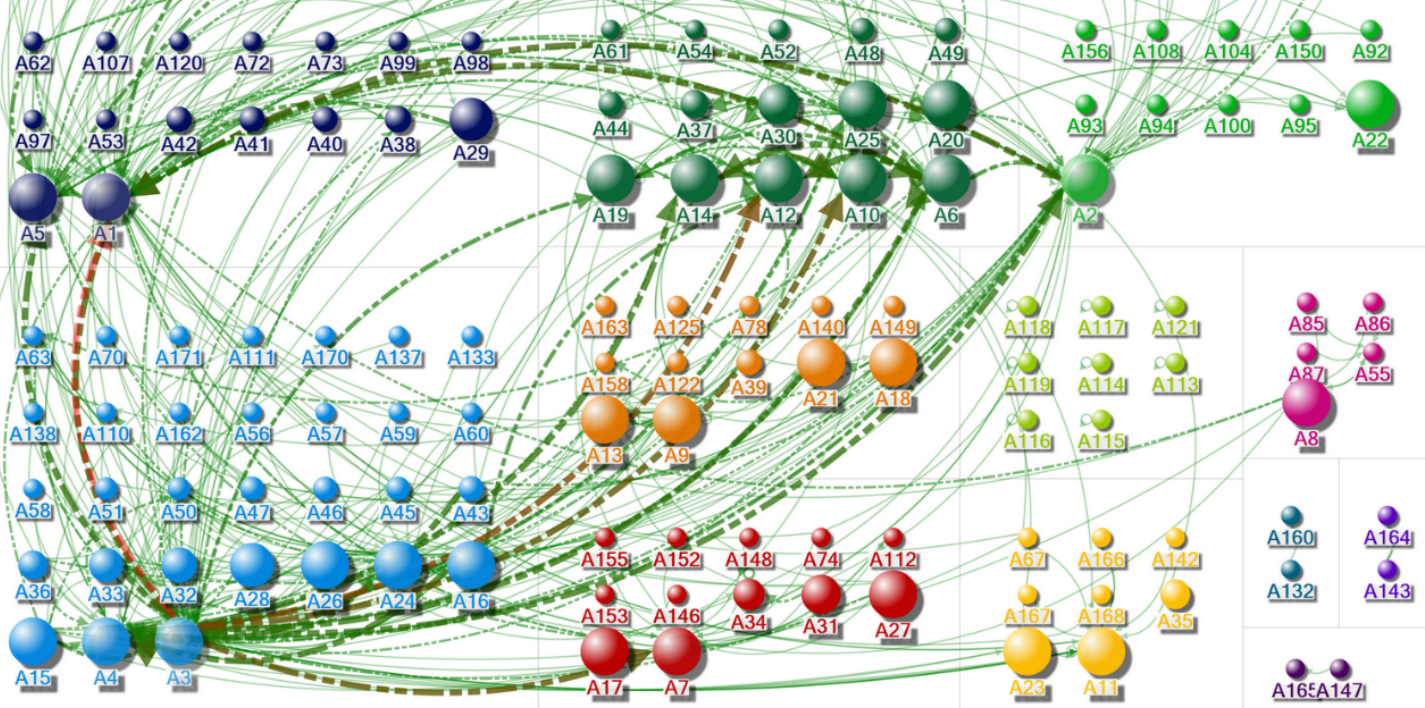

Figure 1. Sociogram for \#DigPed Cairo.

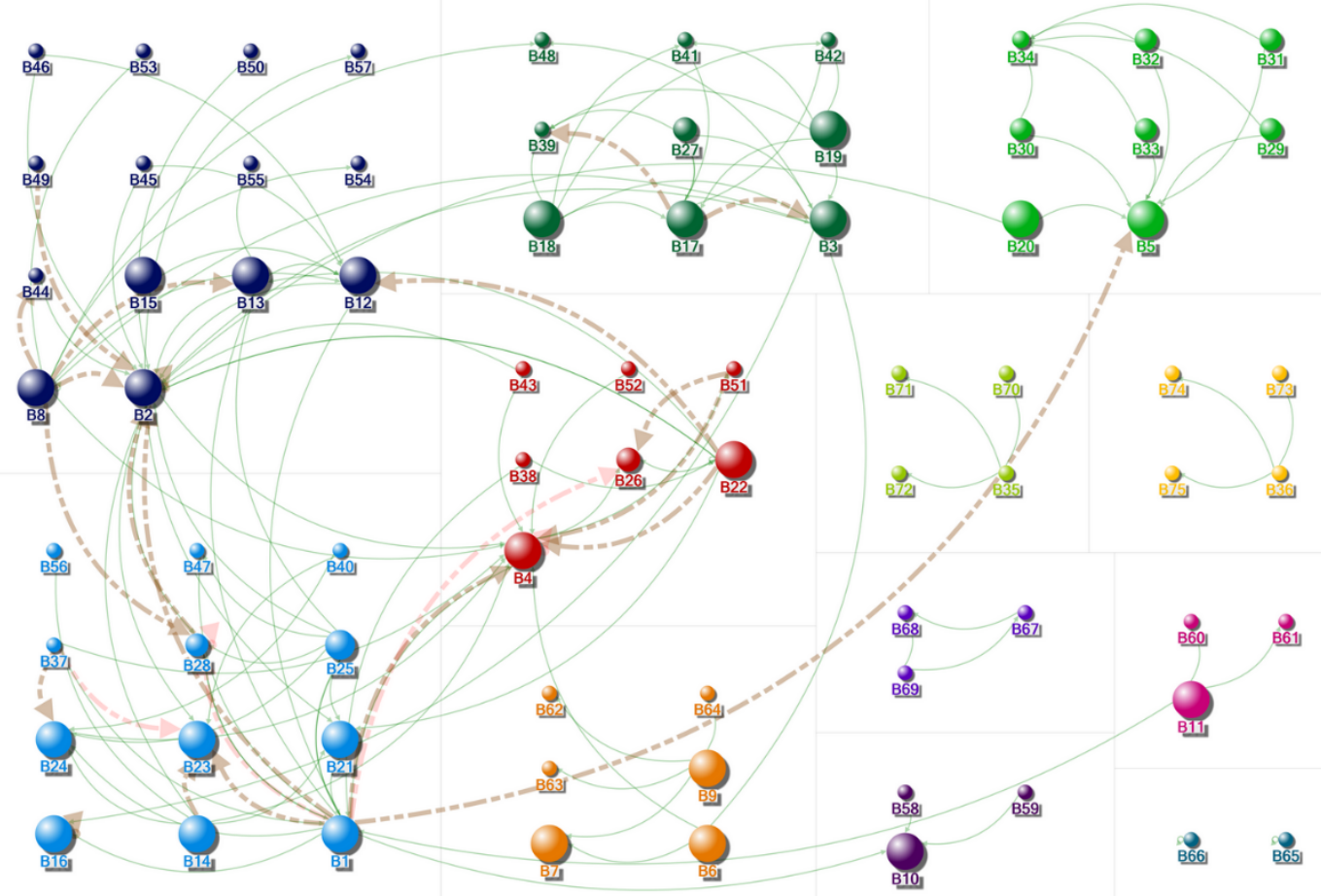

Figure 2. Sociogram for \#DigPed PEI. 


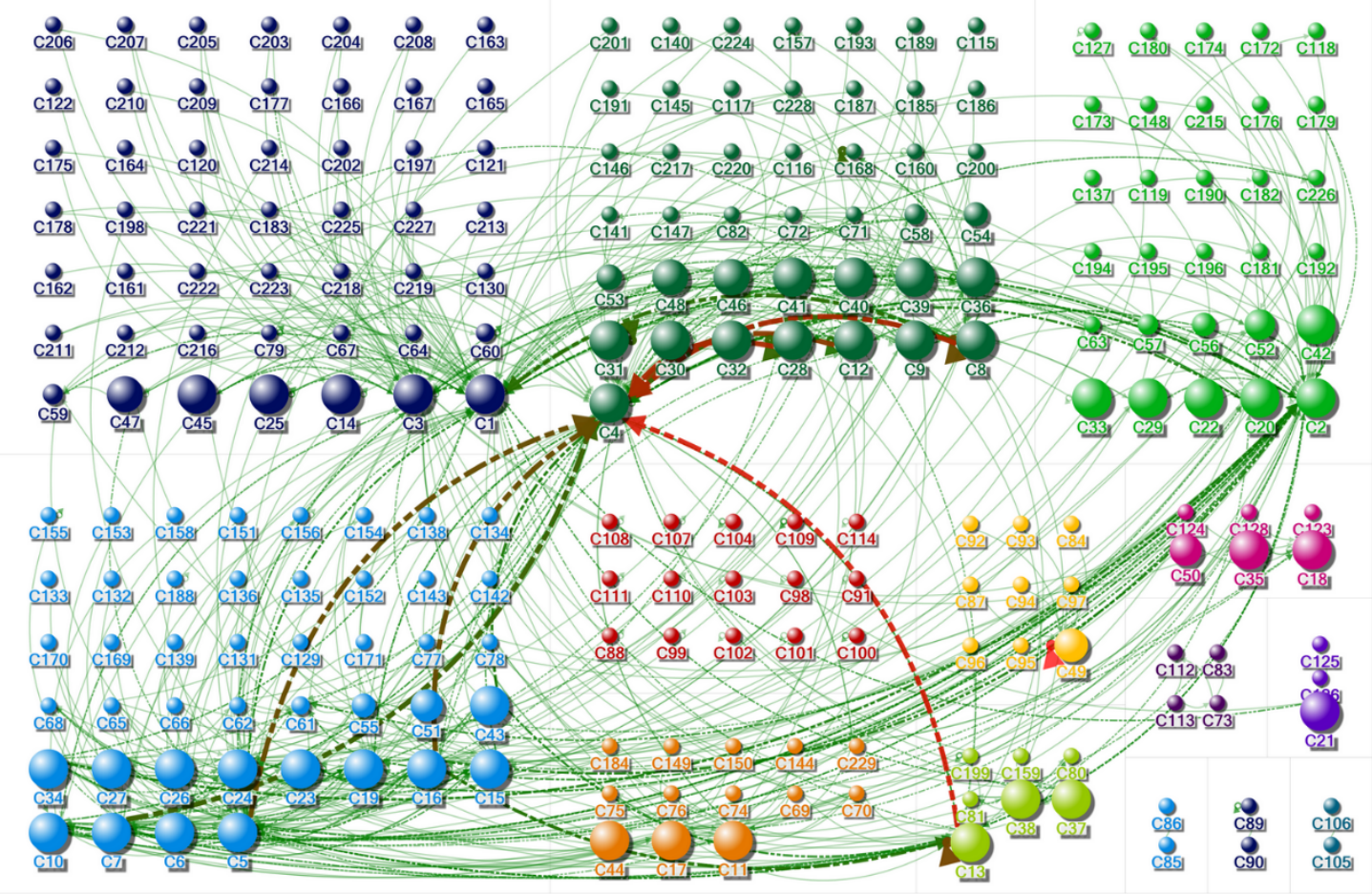

Figure 3. Sociogram for \#DigPed 2017 Summer Institute.

Based on Smith, Rainie, Shneiderman, and Himelboim's (2014) classification of Twitter conversations into six types, we identified \#DigPed Cairo, \#DigPed PEI, and \#DigPed 2017 Summer Institute as unified-tight crowd networks, in which discussions are characterized by highly interconnected people with multiple connections and few isolated participants. In such networks, ideas and conversations can circulate very fast in the conduits of the network because of the tightly woven network connections.

The sociograms above further show that the \#DigPed network was not controlled by a single person, which is something that is typically observed in what are known as ego networks. That is, rather than depending on a focal node/person, power was distributed among different groups of people with a few key influencers more or less in each cluster. These sociograms also show how the conduits of the network formed and how conversations spread across these conduits. Besides, each participant can be located, and their position can be examined through the sociograms.

Hashtags used. To better understand the capacity of the \#DigPed network, we examined the hashtags posted during the events. Hashtags serve as gates that link different networks - and communities - to one another in the networked universe. Thus, they are crucial for seeing how dissemination occurs and what other communities are linked to \#DigPed's discourses. We examined conversations for each \#DigPed event using NodeXL to identify the most used hashtags. The top 10 hashtags for each network were listed, and a cross comparative analysis was conducted (Table 1). 
Table 1

Top Hashtags Used During Three DPL Events

\begin{tabular}{llllll}
\hline \multicolumn{1}{c}{ DigPed Cairo } & \multicolumn{2}{c}{ DigPed PEI } & \multicolumn{2}{c}{ DigPed 2017 Summer Institute } \\
\hline Top Hashtags & Count & Top Hashtags & Count & Top Hashtags & Count \\
\hline digped & 342 & digped & 95 & digped & 684 \\
connectedlearning & 6 & highered & 11 & dplintro & 38 \\
unfis15 & 5 & opendata & 10 & edchat & 32 \\
dgst101 & 5 & oer & 6 & edtech & 11 \\
epp1521 & 5 & oa & 6 & dpintro & 6 \\
highered & 5 & openaccess & 6 & tweetyourshoes & 6 \\
editorspicks & 5 & twitteressay & 3 & sixwordintro & 6 \\
edtech & 4 & edtech & 3 & highered & 6 \\
sketchnotes & 3 & clmooc & 1 & datalit & 6 \\
indieweb & 3 & bonfire & 1 & InstructionalDesign & 3 \\
\hline
\end{tabular}

\#DigPed was naturally the leading hashtag in all events. In addition, in all \#DigPed events, \#highered was a common hashtag, which suggested that higher education was the target audience.

Overall, the use of secondary hashtags during DigPed Cairo, DigPed PEI, and DigPed 2017 Summer Institute was weak compared to the use of the main hashtag (\#DigPed), which suggests that links to outer networks were also weak. However, it should be noted that some other means, such as blogs, live chat sessions, and so on, were also used during event, and this finding is open to further interpretation.

Key influencers. This part of the analysis focused on key nodes - in other words, hubs in the \#DigPed network during each DPL event. The purpose of this analysis was to identify key influencers and see how power was distributed among other nodes. In order to identify key influencers, we examined participants' betweenness centrality values (Table 2). Betweenness centrality is an SNA metric that indicates a node's ability to bridge different nodes and subnetworks. The higher the betweenness centrality value, the stronger and more critical positions can be held in the network.

We first ranked the participants from highest to lowest according to their betweenness centrality values. Following that, we noted the top 20 participants in each event to identify those leading and shaping the \#DigPed network and to find out whether specific nodes dominated the \#DigPed network during and across each event. 
Table 2

Top 20 Participants According to Their Betweenness Centrality Values

\begin{tabular}{lllllll}
\hline & \multicolumn{1}{c}{ DigPed Cairo } & \multicolumn{2}{c}{ DigPed PEI } & \multicolumn{2}{c}{ DigPed 2017 Summer Institute } \\
\hline Node & Betweenness Centrality & Node & Betweenness Centrality & Node & Betweenness Centrality \\
\hline A1 & 7414,494 & B1 & 1554,94 & C1 & 12183,33 \\
A2 & 6600,591 & B2 & 1153,96 & C2 & 7664,48 \\
A3 & 5691,543 & B3 & 905,30 & C3 & 6501,44 \\
A4 & 3934,067 & B4 & 795,41 & C4 & 6162,40 \\
A5 & 2934,341 & B5 & 680,80 & C5 & 3430,62 \\
A6 & 1936,178 & B6 & 583,62 & C6 & 2414,87 \\
A7 & 1882,262 & B7 & 456,00 & C7 & 2253,84 \\
A8 & 1251,000 & B8 & 432,51 & C8 & 2224,78 \\
A9 & 1194,656 & B9 & 354,00 & C9 & 1891,21 \\
A10 & 1152,243 & B10 & 238,00 & C10 & 1763,33 \\
A11 & 1038,979 & B11 & 238,00 & C11 & 1735,54 \\
A12 & 1008,478 & B12 & 233,59 & C12 & 1640,93 \\
A13 & 864,151 & B13 & 154,12 & C13 & 1409,80 \\
A14 & 720,589 & B14 & 152,90 & C14 & 1152,00 \\
A15 & 506,833 & B15 & 121,74 & C15 & 1132,14 \\
A16 & 469,451 & B16 & 118,82 & C16 & 1118,34 \\
A17 & 405,111 & B17 & 108,57 & C17 & 1074,50 \\
A18 & 372,083 & B18 & 102,83 & C18 & 983,65 \\
A19 & 367,353 & B19 & 102,83 & C19 & 815,42 \\
A20 & 347,682 & B20 & 95,86 & C20 & 792,59 \\
\hline
\end{tabular}

According to the analysis based on betweenness centrality metrics, we observed that, in addition to participants (via face-to-face and online means), facilitators and speakers in DPL events held strategic locations in each \#DigPed event. However, the similarity of their betweenness centrality metrics indicate that power was not gathered on a specific node, in contrast, the power of the network was distributed among the top influencers.

\section{Thematic Analysis: Common Themes Across Events}

In this section, similar patterns across all events are noted. All names are anonymized by assigning codes for each participant and for each event.

Strong community. In all events, the sense of community in the network was strong, especially among some of the key influencers we identified via SNA (e.g., A34: "This makes me feel grateful for the *community* that is \#digped et.al. What We Need Is Here"; B1: "So grateful for the time I had @dipedlab PEI and the friends I met. Thanks to B5 B4 B26 B23 \#digped"; A2: "Me and my dear friends A1 and A7 at "the end of all things' (for now) @ digpedlab Cairo. \#digped").

The community included both on-site participants and online participants who were following the events via Twitter (e.g., A6: "I'm so glad the \#DigPed discussion is ongoing. I'm definitely keeping the @TweetDeck column in place for good :)"; C33: "Missing being at Digital Pedagogy Lab this year...but following along from home \#digped").

Participants also introduced people to one another online (e.g., B8: "B53 I want you to meet my friend, B44 \#digped [Name X], meet [Name Y]. [Name Y], meet [Name X]. Now- go change the world of digped"); crowdsourced resources (e.g., B2: "Who should I connect to this \#digped work group on using \#opendata/analytics in \#highered? \#oer \#oa \#openaccess"); and 
shared their lived experience with others (e.g., A26: "All checked in ... almost finished packing ... of to @DigPedLab tomorrow \#digped ... looking forward to seeing C5 and many others ..”).

Virtually Connecting. In each event, Virtually Connecting, defined by the creators as "a connected learning volunteer movement that enlivens virtual conference experiences by partnering those that are at the conference with virtual participants that cannot attend" (Bali, Caines, deWaard, \& Houge, 2016, p. 212) was a venue to bridge on-site and off-site experiences (e.g., C40: "Check out this @VConnecting session with me and a group of other rowdy and generous \#digped troublemakers"; C55: "You can call me a \#digped follower, advocate, and fan! Today, I'm a lurker in the @VConnecting session that C10 is leading :) THANKS!"). This finding is also strengthened by the SNA, as Virtually Connecting was one of the top-visited URLs in all three events.

Limited evidence showing impact. The posts showing impact were limited, although some posts clearly showed a positive change in participants' (online and on-site) lives, including the facilitators of the event (e.g., B1: "Small shifts this week, huge shifts in my life last 5 years thanks to you all. \#digped"; C5: "Today feels like the beginning of a lifechanging experience for me: co-teaching networked/intercultural learning at \#DigPed w C15”).

\section{Thematic Analysis: Prominent Narratives Within Each Event}

In this section, we present the most prominent narratives within each event using thematic analysis. We observed that although participants often shared educational technology tips and advice during the events, the narratives that gained most attention were related to broader pedagogical visions and ideals that evoked strong reactions in \#DigPed participants. Each of the narratives below originated from either a DPL facilitator or a keynote speaker.

Narrative 1 (\#DigPed Cairo): "Love in pedagogical work is an orientation." Love in education was the most prominent narrative in \#DigPed Cairo. The narrative emerged from a discussion in a keynote session, which prompted another DPL facilitator to write a reflective blog post and share it at \#DigPed. This post, titled "On Love, Critical Pedagogy, and the Work We Must Do" (Morris, 2015), was the top URL in the network. Participants either retweeted this post directly (without additional comments) or quoted sections of the post they wanted to share with others. Here we observed how scholars who share similar pedagogical visions amplify and further develop one another's ideas using online and face-to-face opportunities.

Session discussions on love elicited strong emotional reactions from the network, especially from one of the facilitators (e.g., A3: "why is it painful for the academic to admit that love stirs them?"; A3: "One of my fave quotes like...ever A25, A7 \#DigPed. Also: internet has a heart? Internet has a heart!"). Although some participants questioned this narrative, counterperspectives were limited. On one occasion, we observed that a counterperspective was shut down immediately (i.e., A18: "A4, A158, A21 but scale's a big barrier, and I think love is the wrong word. \#DigPed \#hippydippy"; A9: "A18, A4, A158, A21: no I think love is the right word \#digped").

Discussions on love also spread to a Virtually Connecting session (i.e., A3: "“Are we being colonial with our love?' asks the insightful A11 on @VConnecting from \#DigPed").

Narrative 2 (\#DigPed PEI): "Every student can have their own domain -- to share their work, knowledge, memory." In \#DigPed PEI, multiple interrelated narratives on open education were present on the network. The keynote Memory Machines: Learning, Knowing, and Technological Change by Audrey Watters (2016) seemed to gain attention most and prompted discussions on student agency, students' ownership of their data, open data, and access. When the keynote speaker mentioned Domain of One's Own, a University of Mary Washington project, tweets about how it might contribute to student agency quickly spread on 
the network (e.g., B24: “@audreywatters: Domain of One's Own is one of the most important commitments to memory an institution can make \#digped"; B1: "Every student can have their own domain -- to share their work, knowledge, memory.' B23 on Domain of One's Own \#D..."; B2: "No-cost is not the same as free. Our students pay Google with their data. And we've done this without their consent. B23").

The number of tweets posted on this narrative is limited in the data set when compared to the narratives in other two events; however, a similar pattern emerged: An influencer (e.g., a keynote speaker, a facilitator) initiated an idea, which was then amplified through retweets and quotes by other users, including other key influencers.

Narrative 3 (\#DigPed 2017 Summer Institute): "Most stories about student debts/struggles go untold." This narrative emerged from a keynote session by Sara GoldrickRab (UMW Division of Teaching and Learning Technologies, 2017) on "a real but oftenunrecognized crisis [in public education]: basic needs insecurity." As the keynote speaker mentioned in her talk, "most stories about student debts/struggles"-such as student homelessness, debts, hunger-went untold, and the keynote was a platform to bring those issues to surface and call for action. As one participant (C7) tweeted, these were "sobering and sad stories" and gained much attention on the network. Another participant (C8) noted, "I'm moved by@saragoldrickrab focus that we create lots of false narratives about students and college \#digped."

Perhaps this narrative was the most activist of the narratives we've discussed so far, as the keynote speaker was not only calling for empathy for struggling students but also calling for action that will lead to positive change. Participants were encouraged to take action by introducing simple interventions into their teaching, such as adding a section about student well-being into their syllabus and by actively challenging ongoing practices (e.g., C40: "You have until tomorrow and then I'm going to call the newspaper.'@saragoldrickrab on how to INSPIRE YOUR COLLEGE TO TAKE ACTION. \#digped”). As one participant commented, this keynote was an "academic manifesto" (C111: "\#digped \#AcademicManifesto Keynote by Sara Goldrick Rab"). It is interesting to note that the keynote speaker used Twitter effectively to gain attention and invite people to the talk and the discussions-she was one of the top tweeters during the event and joined a Virtually Connecting session where she further discussed the issues in her talk with others (e.g., C29: “@saragoldrickrab: 'framing of interdependence among learners w/in syllabus influences retention' @VConnecting \#digped”; C63: “Amazing conversation happening right now at @VConnecting on syllabi, student empowerment and care \#DigPed"). Perhaps because of this focus on action, theedadvocate.org, a site "devoted to advocating for education equity, reform, and innovation," was one of the most visited domains during the entire \#DigPed 2017 Summer Institute.

\section{Discussion}

In this study, we explored \#DigPed posts during three DPL events held between 2015 and 2017. Our goal was to understand how educational narratives developed and spread on \#DigPed and the nature of their capacities using Tufekci's (2017) capacities and signals framework as an orienting lens. Three prominent narratives emerged from SNA and thematic analysis: "love in pedagogical work is an orientation," "every student can have their own domain - to share their work, knowledge, memory," and "most stories about student debts/struggles go untold."

The narratives that widely spread on the network were not politicized enough to fit directly into the capacities and signals framework. The nature of these narratives led us to 
consider a capacity different from the ones proposed by Tufekci (2017): pedagogic capacity. Here, we define pedagogic capacity as the power to initiate a productive and potentially transformative educational discourse, within oneself and within communities. In addition, we observed that narrative capacity could not simply be explained by spreading a vision: Educational discourses on an open platform like Twitter may evolve and grow in many unexpected directions with active participation, and as such, they open a space for dialogue, not manipulation or imposed action, as we would find in political discourses. Thus, in the context of education, more specifically from a critical viewpoint, we argue that there is a need to consider the pedagogic capacity of critical discourses in tandem with their narrative capacity. This relationship perhaps can be visualized on an $\mathrm{x}$ - and y-axis: While the y-axis shows how far a narrative spreads, the $\mathrm{x}$-axis shows its depth from a pedagogical perspective. Research findings are discussed from this fresh perspective by taking the interplay of pedagogic and narrative capacities into consideration.

First, there was a strong sense of community on the \#DigPed network, particularly among the facilitators. SNA findings also pointed to the formation of a tight community, which was characterized by highly interconnected people with multiple connections. Both facilitators and DPL participants (online and face-to-face), often shared their lived experience (local scenes, moments of anticipation, excitement, realization, etc.) as well as their professional activities publicly. This interplay of professional with the personal is also documented in the literature (see Quan-Haase, Martin, \& McCay-Peet, 2015; Veletsianos \& Kimmons, 2013; Veletsianos \& Stewart, 2016) and is important for community building. However, because of the perceived connectedness and shared pedagogical values/cultural viewpoints, the pedagogic capacity of \#DigPed may be limited. Indeed, although some participants demonstrated counterperspectives and were critical toward the ideas that were spreading in the network, this occurred rarely.

Second, educational visions (e.g., we need to embrace love in education) and facts that evoke strong emotions (e.g., student homelessness) seemed to gain more attention than simply sharing technology tools and tips, and thus, they had more pedagogic capacity. There seems to be a relationship between pedagogic capacity and community: The more comfortable people feel in a public networked space, the more likely they are to reveal emotions in response to a narrative and, hence, increase its pedagogic capacity. However, this argument is open to discussion, as there is a need to consider the complex nuances of community in networked spaces and what it means to share emotions with others in open online spaces.

Third, key influencers (i.e., organizers, keynote speakers) held strategic positions in the network. This observation was supported by the high betweenness centrality values identified via SNA. Thematic analysis also revealed that somebody influential in the network, such as a keynote speaker or an event facilitator, initiated all the narratives identified in this study. Ideas often went back and forth between these influential people and were amplified by others in the network. In addition, key people spread and amplified (a) their own voices through retweets and self-quotes and (b) the voices of people with similar pedagogical views. However, power (the strength of one's position in the network) was not held by a single person in the network, like we would observe in ego networks. Power was shared among a group of people, many of whom were key influencers. We argue that these people can be considered de facto leaders, as they are not expected to take formal leadership roles in online networks; rather, as Tufekci (2017) suggested, over time they "consistently emerge as informal but persistent spokespersons - with large followings on social media" (p. xxiii).

Here, we would like to elaborate on the concept of power and discuss how it relates to networked structures and to \#DigPed in particular. Findings revealed that key influencers had 
a strong capacity to gain attention. These people not only had large personal learning networks but also produced artifacts that stirred the community (e.g., a blog post or a keynote session). They seemed to be comfortable with being public online and were good speakers: They had charisma. In a way, key influencers had become gatekeepers: They acted as "innovator, change agent, communication channel, link ... opinion leader ... and facilitator" (Metoyer-Duran, 1993; we did not observe four of the roles suggested by Metoyer-Duran: intermediary, helper, adapter, and broker). Gatekeeping was distributed across face-to-face and online channels. It is important to note that in this context, gatekeeping was not manipulative or restrictive. Rather, it acted as a call to understand and consider a worldview; it was a pedagogical act. Thus, this research supports the perspective that gatekeeping is a "ubiquitous and diverse phenomenon" (Barzilai-Nahon, 2009; Gursakal \& Bozkurt, 2017, p. 77). We observed that the \#DigPed community reinforced the role of the gatekeepers by their responses to the emerging narratives.

Overall, findings suggest that although a network like \#DigPed is open to all, there are hidden power structures that shape the network activity. Findings also align with Stewart's (2015) argument that "hierarchies of influence relate to identity and attention, rather than [institutional] role" (p. 306) on an open platform like Twitter. These hierarchies of influence are not taught through formal practices (such as staff induction events or earned ranks) but learned and earned through ongoing participation in a community, both through professional and personal means. As Veletsianos (2012), citing Tufekci, noted "non-scholarly social interaction is "essential to forging bonds, affirming relationships, displaying bonds, and asserting and learning about hierarchies and alliances' (cf. Tufekci, 2008, p. 546)"; however, these interactions may not necessarily "lead to positive outcomes" (p. 11).

\section{Conclusion}

Multiple implications in relation to pedagogic and narrative capacities of online networks like \#DigPed can be drawn from this research.

There is a need to strengthen the pedagogic capacity of educational narratives: Blogs, Twitter chats, online meetings, and keynotes/talks can be considered intersectional spaces for critical discourse, as these spaces have the potential to cut across social identities (academic and personal), geographies (on-site and global), and time (past and present). Thus, these are powerful spaces for pedagogic practice: They have the power to initiate a narrative and open up venues for discussion, dialogue, and inspiration. However, in the context of hashtag communities, more effort is needed to reach a broader audience - an audience that goes beyond the immediate network community - and enhance the pedagogic capacity of critical narratives. A good example for strengthening narrative and pedagogic capacities is Audrey Watters (the keynote speaker at Digital Pedagogy Lab PEI). Watters, using her own resources, published the transcript of her DPL keynote talk on her site, which enabled others to access, amplify, and build on her arguments regardless of the extent of their engagement with \#DigPed or DPL events. Another example for enhancing pedagogic and narrative capacities is Virtually Connecting (see Bali, Caines, deWaard, \& Houge, 2016) — informal online meetings bridging onsite and offsite experiences - as it opens up a space of dialogue that is independent, inclusive, and organically developed. Effective use of hashtags might also increase the pedagogic capacity of a narrative, as hashtags are important outlets for connecting different communities with one another. All the narratives we have discussed in this paper have relevance to K-12 or adult education; however, in hashtag analysis we observed that \#HigherEd was a common hashtag in all three events, and other areas somehow seem to have been ignored. With strategic use of hashtags, \#DigPed's critical discourses could be expanded more effectively to other formal and informal educational contexts. 
There is a need to acknowledge the power dynamics in open networks: This research supports the perspective that online spaces are organized by hidden hierarchies marked by influence. The algorithms that are imposed on us and our everyday activities create a hybrid structure that shifts between horizontal and top-down structures. On an open platform like Twitter, although many voices can be heard and theoretically the space is open to all, people with influence still hold strategic positions in the network. In the \#DigPed network, power was held by groups and was defined by relationships, similar pedagogic values, output, and presence.

Acknowledging power in open networks is useful for challenging false assumptions about openness - mainly the notion that open educational networks (like an educational hashtag community on Twitter) promote equality and lead to positive change regardless of one's position in the network. Thus, we strongly echo Farrow's (2017) call to develop deeper "critical reflexivity" (p. 142) in open contexts and argue for a need to have more discussions on privileged or subjective positions in networked communities.

There is a need to further investigate the complex nuances of gatekeeping: We call for a need to further investigate the nuances of gatekeeping and the types of capital that strengthen the positions of influencers, such as economic and social capital. It is important to note that social capital in online networks is strongly related to one's capacity to influence. For instance, on Twitter, the number of tweets and their impressions, the size of one's personal learning network, and the number of followers are mechanisms to determine capacity. However, mixed methods studies on capital in social networks should be conducted to better understand what these metrics might actually represent in social contexts.

Finally, we call for future research studies to explore the impact of critical educational narratives on practice and policy using qualitative methodologies. This is important, because metrics alone do not show us how narratives that diverge from common practices and norms may change people's everyday practice and, equally important, how they are further shaped by lived experience. We aim to conduct a follow-up study on \#DigPed narratives to tackle this complex, yet significant area of research.

\section{Acknowledgement}

This research was supported by Anadolu University Scientific Research Projects Commission under the grant no: 1805E123.

We would like to thank Dr. Ela Akgun-Ozbek from Anadolu University for her valuable comments on the initial version of the research manuscript.

\section{Author's Notes}

An extended abstract of this paper was presented at Ireland International Conference in Education (IICE), April 23-26, Dublin, Ireland.

The names bell hooks and danah boyd are intentionally written in lowercase because the cited researchers use their full names in this style. 


\section{References}

Bali, M., Caines, A., deWaard, H., \& Houge, R. J. (2016). Ethos and practice of a connected learning movement: Interpreting Virtually Connecting through alignment with theory and survey results. Online Learning, 20(4), 212-229.

Barzilai-Nahon, K. (2009). Gatekeeping: A critical review. Annual Review of Information Science and Technology, 43(1), 1-79.

boyd, d. (2010). Social network sites as networked publics: Affordances, dynamics, and implications. In Z. Papacharissi (Ed.), Networked self: Identity, community, and culture on social network sites (pp. 39-58). New York: Routledge.

Bruns, A., \& Burgess, J. (2015). Twitter hashtags from ad hoc to calculated publics. In N. Rambukkana (Ed.), Hashtag publics: The power and politics of discursive networks (pp. 13-28). Peter Lang, New York.

Carpenter, J. P., \& Krutka, D. G. (2014). How and why educators use Twitter: A survey of the field. Journal of Research on Technology in Education, 46(4), 414-434.

Charmaz, K. (2006). Constructing grounded theory: A practical guide through qualitative analysis. London: Sage Publications.

Clauset, A., Newman, M. E., \& Moore, C. (2004). Finding community structure in very large networks. Physical Review E, 70(6), 1-6.

Creswell, J. W. (2012). Educational research: Planning, conducting, and evaluating quantitative and qualitative approaches to research. Upper Saddle River, NJ: Merrill/Pearson Education.

Creswell, J. W., \& Plano Clark, V. L. (2011). Designing and conducting mixed methods research (2nd ed.). Thousand Oaks, CA: Sage.

DPL. (n.d.). Philosophy. Retrieved from http://www.digitalpedagogylab.com/

Fang, J. (2016). In defence of hashtag activism. Journal of Critical Scholarship on Higher Education and Student Affairs, 2(1), 137-142.

Farrow, R. (2017). Open education and critical pedagogy. Learning, Media and Technology, $42(2), 130-146$.

Forte, A., Humphreys, M., \& Park, T. (2012). Grassroots professional development: How teachers use Twitter. Proceedings of the Sixth International AAAI Conference on Weblogs and Social Media (pp. 106-103). Dublin, Ireland.

Gillespie, T. (2014). The relevance of algorithms. In T. Gillespie, P. Boczkowski, \& K. Foot (Eds.), Media technologies: Essays on communication, materiality, and society (pp. 167-194). Cambridge, MA: MIT Press.

Gursakal, N., \& Bozkurt, A. (2017). Identifying gatekeepers in online learning networks. World Journal on Educational Technology: Current Issues, 9(2), 75-88.

Greene, J. C. (2007). Mixed methods in social inquiry. San Francisco: John Wiley \& Sons.

Hansen, D., Shneiderman, B., \& Smith, M. A. (2010). Analyzing social media networks with NodeXL: Insights from a connected world. Burlington, MA: Morgan Kaufmann.

Iiyoshi, T., \& Vijay Kumar, M. S. (2008). An invitation to open up the future of education. In T. Iiyoshi, \& M. S. Vijay Kumar (Eds.), Opening up education. Cambridge, MA: The MIT Press. 
Koutropoulos, A., Abajian, S. J., deWaard, I., Hogue, R. H., Keskin, N. O., \& Rodriguez, C. O. (2014). What tweets tell us about MOOC participation. International Journal of Emerging Technologies in Learning (iJET), 9(1), 8-21.

Metoyer-Duran, C. (1993). Information gatekeepers. Annual Review of Information Science and Technology, 28, 111-150.

Morris, S. M. (2015). On love, critical pedagogy, and the work we must do [Blog post]. Retrieved from https://www.seanmichaelmorris.com/on-love-critical-pedagogy-andthe-work-we-must-do/

Quan-Haase, A., Martin, K., \& McCay-Peet, L. (2015). Networks of digital humanities scholars: The informational and social uses and gratifications of Twitter. Big Data \& Society, 2(1).

Smith, M., Rainie, L., Shneiderman, B., \& Himelboim, I. (2014). Mapping Twitter topic networks: From polarized crowds to community clusters (Research report). Retrieved from http://www.pewinternet.org/2014/02/20/mapping-twitter-topic-networks-frompolarized-crowds-to-community-clusters/

Stewart, B. (2015). Open to influence: What counts as academic influence in scholarly networked "Twitter" participation. Learning, Media and Technology, 40(3), 287-309.

Stewart, B. (2016). Collapsed publics: Orality, literacy, and vulnerability in academic Twitter. Journal of Applied Social Theory, 1(1), 61-86.

Tracy, S. J. (2013). Qualitative research methods. West Sussex, UK: Wiley-Blackwell.

Tufekci, Z. (2017). Twitter and tear gas: The power and fragility of networked protest. New Haven, MA: Yale University Press.

Veletsianos, G. (2012). Higher education scholars' participation and practices on Twitter. Journal of Computer Assisted Learning, 28(4), 336-349.

Veletsianos, G., \& Kimmons, R. (2012). Assumptions and challenges of open scholarship. The International Review of Research in Open and Distributed Learning, 13(4), 166189.

Veletsianos, G., \& Kimmons, R. (2013). Scholars' and faculty members' lived experiences in online social networks. The Internet and Higher Education, 16, 43-50.

Veletsianos, G., \& Stewart, B. (2016). Discreet openness: Scholars' selective and intentional self-disclosures online. Social Media and Society, 1(11), 1-11.

UMW Division of Teaching and Learning Technologies. (2017). A real but oftenunrecognized crisis [in public education]: Basic needs insecurity. Retrieved from https://www.youtube.com/watch? $\mathrm{v}=8 \mathrm{vZoH} 07-\mathrm{xdc}$

Watters, A. (2016). Memory machines: Learning, knowing, and technological change. Retrieved from http://hackeducation.com/2016/07/13/memory-machines

Yang, G. (2016). Narrative agency in hashtag activism: The case of \#BlackLivesMatter. Media and Communication, 4(4), 13-17. 
Appendix A

\begin{tabular}{|c|c|c|}
\hline \multicolumn{3}{|l|}{ Sample Open Coding } \\
\hline Tweet & Open Codes & Researcher Notes \\
\hline $\begin{array}{l}\text { A3: "'Love in pedagogical } \\
\text { work is an orientation. It's a } \\
\text { commitment to the } \\
\text { personhood of learners.' } \\
\text { \#DigPed A1 [LINK]"' }\end{array}$ & $\begin{array}{l}\text { Q-Blog-Fac-Love } \\
\text { (Quote, Blog post, } \\
\text { Facilitator, Love) }\end{array}$ & $\begin{array}{l}\text { A facilitator tweets a link to } \\
\text { a blog post on love in } \\
\text { education, written by } \\
\text { another DPL facilitator (post } \\
\text { is titled "On Love, Critical } \\
\text { Pedagogy, and the Work We } \\
\text { Must Do"). }\end{array}$ \\
\hline $\begin{array}{l}\text { B8: "B53 I want you to meet } \\
\text { my friend, B44 \#digped } \\
\text { [Name X], meet [Name Y]. } \\
\text { [Name Y], meet [Name X]. } \\
\text { Now- go change the world } \\
\text { of digped" }\end{array}$ & $\begin{array}{l}\text { Fri-Bro-DigPedCo } \\
\text { (Friendship, Brokering, } \\
\text { Reference to DigPed } \\
\text { Community) }\end{array}$ & $\begin{array}{l}\text { Participant introduces a } \\
\text { friend to another person } \\
\text { online. There is a direct } \\
\text { reference to DigPed: "the } \\
\text { world of digped." Could this } \\
\text { be the online DigPed } \\
\text { community? } \\
\text { Added the code "Brokering" } \\
\text { based on Metoyer-Duran } \\
\text { (1993); search for more } \\
\text { evidence on this. }\end{array}$ \\
\hline $\begin{array}{l}\text { C7: "Amazing narratives via } \\
\text { @sarahgoldrickrab - many } \\
\text { sobering and sad stories she } \\
\text { shares some of her subjects. } \\
\text { \#DigPed" }\end{array}$ & $\begin{array}{l}\text { Na-Key-EmRes (Narrative, } \\
\text { Keynote Speaker, Emotional } \\
\text { Response) }\end{array}$ & $\begin{array}{l}\text { Participant reveals an } \\
\text { emotion (sadness) in } \\
\text { response to a narrative by } \\
\text { Sarah Goldrick-Rab } \\
\text { (keynote speaker). }\end{array}$ \\
\hline
\end{tabular}

Note. All names are anonymized by assigning a code for each participant and for each event. 
Appendix $B$

\begin{tabular}{|l|l|}
\hline \multicolumn{2}{|l|}{ Sample Entries From the Researchers' Collaborative Journal } \\
\hline Date and Researcher Initials & Entry \\
\hline $\begin{array}{l}\text { Sept. 4, } 2017 \\
\text { Kras Bozkurt \& Suzan }\end{array}$ & $\begin{array}{l}\text { Suzan: Thinking about the narratives that have spread on } \\
\text { digped, their reach... when were they most popular? } \\
\text { Leaders in these narratives... (I think we can frame them as } \\
\text { de facto leaders like Tufekci mentions in her book: not } \\
\text { selected formally but they act as leaders.) }\end{array}$ \\
$\begin{array}{l}\text { Aras: (1) We can, maybe, talk about the "virality" of these } \\
\text { thoughts... (2) Though very shallow, we can do sentiment } \\
\text { analysis for each event, (3) as well as hashtags, we have } \\
\text { also data for the most referred links. these can be examined } \\
\text { as a source of data and discourses in these links, (4) to } \\
\text { examine de facto leaders, we can examine these nodes (ppl) } \\
\text { from different aspects: top-mentioned, top-tweeted, top- } \\
\text { replied etc. }\end{array}$ \\
\hline $\begin{array}{l}\text { Sept. 8, 2017 } \\
\text { Suzan Koseoglu }\end{array}$ & $\begin{array}{l}\text { Reflecting on the Google Hangout with Aras. } \\
\text { - Aras mentioned in the hangout that we don't swim in the } \\
\text { same water on Twitter. How do algorithms impact our } \\
\text { engagement with the hashtag? To what extent do we } \\
\text { know about the algorithms imposed on us? }\end{array}$ \\
$\begin{array}{l}\text { We assume that Twitter is a networked public space; is it a } \\
\text { space of "personalised, calculated publics" instead? } \\
\text { - Researcher's involvement with the research field and how } \\
\text { that impacts the process. How will the community feel } \\
\text { about our findings? Our own assumptions and biases? }\end{array}$ \\
\hline
\end{tabular}

Note. Researchers' collaborative journal was a space for the researchers to reflect on the research process and document their thoughts. 